\title{
Why Have a Theory of Law and Technological Change?
}

\section{Lyria Bennett Moses*}

\section{INTRODUCTION}

While at law school, I often found that the most interesting hypotheticals and research topics were based on some new (or once new) technology. Examples might be taken from a range of technologies and doctrinal fields: e-commerce and contract law, electronic documents and litigation, organ transplantation and property law, the rise of industry and tort law, computer hacking and criminal law, and so forth. My interest in these types of questions is not unique. Over forty law journals claim to deal with issues of law and technology. ${ }^{1}$ While some of these are limited to specific technologies or to particular areas of law (such as intellectual property), there are many that are interested in the same spectrum of issues as myself. Given this scholarly focus, one might expect to find a group of scholars commenting on "law and technology," in the same way as one finds groups of scholars looking at "law and economics" or "law and literature." The study of technology as such is certainly an important topic within other

(C) 2007 Lyria Bennett Moses.

* Lyria Bennett Moses, B.Sc. (Hons), LL.B. (UNSW), LL.M. (Columbia) Lecturer, University of New South Wales; JSD Candidate, Columbia Law School. The author would like to thank Frank Pasquale, Kieran Tranter, Gaia Bernstein, Arthur Cockfield, Harold Edgar, Peter Strauss, Bill Sage, Jennifer Chandler, and Karen Eltis for their insights, as well as the peer reviewer and faculty and student editors at the Minnesota Journal of Law, Science and Technology for their helpful comments.

1. Search performed on Washington \& Lee Law School's Law Journal: Submissions and Rankings website, available at http://lawlib.wlu.edu/LJ/ (last visited Apr. 7, 2007). 
disciplines, including philosophy, history, and sociology. ${ }^{2}$ Among legal scholars, however, interest in a general theory of law and technology is relatively recent. ${ }^{3}$

The rationale for a general theory of law and technology, or a general theory of law and technological change, is not immediately obvious. ${ }^{4}$ Such a topic risks being both too broad and too narrow. It appears too general because of the significant differences between technologies - the birth control pill raises very different legal questions from those raised by nuclear power. At the same time, it risks reifying technology. Technology might also be too narrow a focus-efforts might be more efficiently directed at developing a more general theory, such as a theory of law and social change. My goal in this essay is to justify a focus on "law and technological change" rather than any narrower or broader topic. I begin in Part II by setting out a definition of technology and technological change. Part III sets out some of the general observations that might be made about law and technological change and the benefits of broadening one's analysis to look at technology as a category. Part IV distinguishes a theory of law and technological change from even broader topics, in particular, law and changes in knowledge and law and social change. Part V concludes by setting out some of the potential

2. Journals addressing these issues include: Society for Philosophy and Technology Quarterly Electronic Journal; Bulletin of Science, Technology and Society; Technology and Culture.

3. See Gaia Bernstein, Accommodating Technological Innovation: Identity, Genetic Testing, and the Internet, 57 VAND. L. REV. 965 (2004) (comparing the impact of genetic testing and the Internet on identity interests, showing how similar problems arise in different settings); Gaia Bernstein, The Paradoxes of Technological Diffusion: Genetic Discrimination and Internet Privacy, 39 CONN. L. REV. 243 (2006) (discussing how, where a technology has a negative impact on social values, certain features of a technology's diffusion can create inefficient situations); Arthur Cockfield, Towards a Theory of Law and Technology, 30 MAN. L.J. 383 (2004) (evaluating different interpretive responses to technological change); David Friedman, Does Technology Require New Law?, 25 HARV. J.L. \& PUB. POL'Y 71, 71 (2001); Monroe E. Price, The Newness of New Technology, 22 CARDOZO L. REV. 1885, 1888 (2001). In the field of international law, see generally Joseph W. Dellapenna, Law in a Shrinking World: The Interaction of Science and Technology with International Law, 88 KY. L.J. 809 (1999-2000) and Colin B. Picker, A View From 40,000 Feet: International Law and the Invisible Hand of Technology, 23 CARDOZO L. REV. 149 (2001). See also LAURENCE TRIBE, CHANNELING TECHNOLOGY THROUGH LAW (1972).

4. For discussions, see Law and Technology Theory, http://techtheory.blogspot.com/ (last visited Apr. 7, 2007). 
advantages of theorizing about law and technology.

\section{WHAT IS TECHNOGICAL CHANGE?}

The term "technology" is not univocal; it has a range of meanings and has been employed in different ways in different contexts. Its modern history is quite short. ${ }^{5}$ It has been used to refer to: (1) tools and techniques; (2) organized systems such as factories; (3) applied science; (4) those methods that achieve, or are intended to achieve, a particular goal such as efficiency, the satisfaction of human needs and wants, or control over the environment; and (5) the study of or knowledge about such things. ${ }^{6}$ The term "technology" thus sometimes includes what might also be called "technique"; making organization, bureaucracy, and even law itself into "technologies." Such extended meanings of the term "technology" are not, however, what law journals focused on "technology" usually mean by the term. ${ }^{7}$ The study of the "technologies" of corporate organization, government bureaucracy, and law tend to be left to experts in corporate law, administrative law, and legal theory (or law and social theory) respectively. Since locating a single definition of technology is impossible, this essay will adopt a narrower focus.

When lawyers claim to be interested in issues surrounding law and technology, it is usually related to questions of how the law ought to relate to activities, entities, and relationships made possible by a new technology. As technology changes, we can do things, make things, and form connections that were not previously practicable. ${ }^{8}$ For

5. Eric Schatzberg, Technik Comes to America: Changing Meanings of Technology Before 1930, 47 TECH. \& CULTURE 486 (2006).

6. LARRY A. HICKMAN, PHILOSOPHICAL TOOLS FOR TECHNOLOGICAL Culture Putting Pragmatism to Work 11 (2001); Carl Mitcham, Thinking Through Technology: The Path Between Engineering and Philosophy 116-17, 150, 160, 308 (1994).

7. There has, however, been some work extending the general critique of technology, such as, JACQUES ELLUL, THE TECHNOLOGICAL SOCIETY (John Wilkinson trans., Vintage Books 1964) to criticize unduly technical approaches to law. See also, Franz A. Foltz \& Frederick A. Foltz, Technology, Religion and Justice: The Problems of Disembedded and Disembodied Law, 26 BULL. SCI. TECH. \& SOC. 463 (2006).

8. Of course, new forms of conduct made possible by technological change were always theoretically possible. However, for practical purposes, they were only available after the relevant technological change. 
example, the development of in vitro fertilization meant that: 9

- Biologically infertile couples could bear and raise a genetically related child;

- There was a new field of activity, providing in vitro services, that could be carried out in various ways;

- An existing entity (the embryo) was moved to a new location, creating the possibility of additional tests and manipulations.

As further illustration, one topic, rail transportation, gave rise to very different potentialities:

- The possibility of transport by rail gave rise to an incentive to build tracks across land belonging to another.

- The possibility also created a new field of activity, running a railroad network, which required significant investments of capital as well as centralized organization.

- In the construction of railroads, new "things" were manufactured and used, including trains, carriages, and their components (brakes, couplers, etc.).

- Once constructed, railroads enabled (relatively) rapid transportation by land but only along fixed routes.

- The operation of railroads created the potential for new types of accidents (such as collisions of trains with pedestrians, vehicles, employees, and animals) and increased the extent of other harms (such as environmental damage).

A definition that focuses on the relationship between technological change and new forms of conduct was offered by David Schön in 1967. Schön defines technology as "any tool or technique, any product or process, any physical equipment or method of doing or making, by which human capability is extended." 10 This essay concentrates on technology as being that which overcomes physical, as opposed to legal, normative or self-imposed constraint.

9. Lyria Bennett Moses, Legal Responses to Technological Change: The Example of In Vitro Fertilization, 6 MINN. J. L. SCI. \& TECH. 505, 514-15 (2005).

10. Donald Schön, Technology And Change 1 (1967); see also LANGDON WINNER, AUTONOMOUS TECHNOLOGY 98, 178-79 (1977). 
The very different technologies of in vitro fertilization and railroad transportation can be used to illustrate the relationship between increases in human capacity and legal dilemmas. ${ }^{11}$ For example, in the case of assisted reproduction (including in vitro fertilization): 12

- There was a perceived need to either prohibit in vitro fertilization, or at least to regulate it, in order to respond to health, safety, and social concerns.

- It was uncertain whether in vitro embryos would be treated as persons, property, or something else.

- In most jurisdictions, there was no criminal penalty for "stealing" embryos, which could not be treated as property having a fixed value.

- At least one case had held that a woman using the sperm of a man who was not her husband for the purposes of assisted reproduction had committed adultery.

Problems that, at first glance, appear quite different arose from the introduction of rail travel:

- There was a perceived need to develop special laws to respond to the physical dangers posed by railroads. ${ }^{13}$

- The need to construct rail tracks confronted legal uncertainty as to whether an agreement between a railroad and a landowner permitting the former to construct and use tracks across the land of the latter could give rise to a proprietary right. ${ }^{14}$

- The obligations generally imposed on common carriers, such as the requirement that goods be delivered to consignees on their own premises, proved impractical for railroads. ${ }^{15}$

- The assumption that A's right to pass through B's land was intended to be personal rather than

11. For discussion of a broader range of technologies, see Lyria Bennett Moses, Recurring Dilemmas: The Law's Race to Keep up with Technological Change, (2007) U. ILL. J.L., TECH. \& POL'Y (forthcoming).

12. Bennett Moses, supra note 9, at 522-536.

13. E.g., Federal Safety Appliances Act, 49 U.S.C. § 20301 (1893).

14. Compare Hemmingway v. Fernandes, 13 Simons. 228, 60 E.R. 89 (1842) (covenant to erect a railway across the land of another in exchange for payment of a toll is proprietary) with Keppell v. Bailey, 2 My. \& K. 517, 39 E.R. 1042, 1048 (1834) (covenant to use an existing railway in exchange for payment of a toll not proprietary).

15. JAMES W. ELY, JR., RAILROADS AND AMERICAN LAW 182 (2001). 
proprietary unless A owned property nearby made little sense where A was a railroad company, rendering the general rule against easements in gross obsolete. ${ }^{16}$

By demonstrating that problems generated by the very different technologies of assisted reproduction and rail transportation arise for similar reasons, this essay will demonstrate the advantages of developing a theory of law and technological change. Lawyers tend to break along technological lines (health lawyers, cyber-lawyers, etc.) or doctrinal lines (contract lawyers, tort lawyers, etc.). In most circumstances, a specific focus is important. No single theory can decide whether regulation is necessary and, if so, in what form, for every conceivable type of technology. Again, the birth control pill raises very different issues to those raised by nuclear power. No theory of law and technology will answer all legal questions for all technologies. It can, however, offer those who work in particular areas some useful insights.

\section{ZOOMING OUT TO TECHNOLOGICAL CHANGE}

Although each technological change may have very different impacts on both law and society, useful observations can be made at a more general level. The current state of technology limits, in practice, what actions we can perform, what objects we can create, and what relationships we can form. It is thus common for technological change to impact the law, which limits what actions we may perform, what objects we may create and use, and what relationships will be recognized. Before something becomes possible, there is no need to decide how it is treated under existing legal rules or whether it ought to be permitted, prohibited, required, or encouraged. These questions arise (with increasing urgency) when a new technological development is conceived, developed, and diffused into society.

Although not every technology generates litigation and legal scholarship, technological change is often the occasion for legal problems. Four reasons why legal change might be a necessary response to technological change are:

1. New rules. We need to regulate certain new forms of conduct and new, specially tailored laws are required to do

16. John CRIBbet, PRINCIPles of the LAW OF PROPERTY 342 (2d ed. 1975). 
this. In some cases, it may even be appropriate to ban a particular technology or particular applications of that technology.

2. Uncertainty. The law is uncertain as it applies to new forms of conduct. In other words, it is not clear whether such conduct is commanded, prohibited, or authorized. Existing rules need to be clarified.

3. Scope of rules. Existing rules were not formulated with new technologies in mind. Thus, some rules in their current form inappropriately include or exclude new forms of conduct.

4. Justification for rules. Some existing rules are explicitly or implicitly based on a premise that no longer exists, and are thus no longer justified [or important or costeffective]. ${ }^{17}$

The examples of legal problems arising from the introduction of assisted reproduction and rail transportation set out in Part II above fit into these four categories. Not every technology will raise issues in each of the four categories; some technologies, such as electric can openers, raise few, if any, legal issues. Nevertheless, as technology changes, as new entities, activities, and relationships come into being, there is at least the potential for issues to arise in the above four categories.

This classification scheme has several useful functions. Understanding the ways in which legal rules fail to achieve their purposes in the face of technological change can assist in improving techniques of legislative drafting. Having a clearer understanding of how legal problems arise in the face of technological change can help in creating a legal reform agenda at an early stage of a technology's development. In particular, it helps with advance thinking about the legal problems that might arise once a new technology diffuses throughout society.

Ironically, one of the greatest benefits in understanding the contexts in which technological change generates legal problems is to avoid exaggerating the dilemmas posed by new technologies. Over-emphasis on the technological angle in discussing legal and social problems is evident in various contexts. James Boyle described how journalists sought his comment on the "Internet angle" for ordinary crimes that

17. Bennett Moses, supra note 9, at 517. 
happened to involve a website or email.18 He gives the example of a murderer using an email to get a victim to turn up somewhere-one would not emphasize the technological link had an older technology (say, a telephone) been used. Similar problems arise in evaluating technology's impact on society. For example, it seems more plausible to conclude that the Internet (on average) causes depression than to say that conversation, on average, has the same effect (even if, statistically, that were true). ${ }^{19}$ Judges occasionally fall into the same trap of assuming that because events took place on the Internet, the law must be different. ${ }^{20}$ Despite occasional statements that some new technology changes everything, ${ }^{21}$ legal problems stemming from technological change are relatively rare and quite specific. Most of the time, a law predating technological change will apply in the new circumstances without any confusion. For example, traffic rules continue to apply to cars with electric windows, and no sane person would seek to challenge these laws as inapplicable or write an article calling for the law to be clarified. A Massachusetts court had little difficulty deciding that a name typed at the end of an email could be a signature, as it was directly analogous to a typed name at the end of a telegram, which had already been accepted as a signature in earlier cases. ${ }^{22}$ Suggestions that law is unable to keep up in a race against technology or that law does not apply to a new technology such as the Internet overstate the extent of the problem. ${ }^{23}$ Understanding the circumstances in which technological change does create legal problems highlights the fact that many legal problems are technology-independent. It

18. James Boyle, Foucault in Cyberspace: Surveillance, Sovereignty and Hard-Wired Sensors, 66 U. CIN. L. REV. 177 (1997).

19. Sherry Turkle, "Spinning" Technology: What We Are Not Thinking About When We Are Thinking About Computers, in TECHNOLOGICAL VISIONS: THE Hopes AND FEARS THAT SHAPE NEW TECHNOlOGIES 19, 22 (Marita Sturken et al. eds., 2004).

20. E.g., Macquarie Bank v. Berg, 1999 Austl. Def. Rep. 53-035 (Sup. Ct. N.S. Wales 1999) (refusing to grant an injunction to restrain defamation because of concerns about variation in defamation laws across jurisdictions).

21. See, e.g., David R. Johnson \& David Post, Law and Borders: The Rise of Law in Cyberspace, 48 STAN. L. REV. 1367 (1996) (arguing that new rules will emerge to govern within cyberspace a wide range of new phenomena that have no parallel in the non-virtual world).

22. Shattuck v. Klotzbach, 14 Mass. L. Rptr. 360 (Mass. Super. Ct. 2001).

23. See Bennett Moses, supra note 9, at 515-517. Cf. Johnson \& Post, supra note 21 (in relation to the Internet). 
also confirms that, even though problems associated with new technologies seem new, problems of the same type have arisen previously in relation to technologies no longer perceived as "new." Observing techno-legal debates of the past helps defuse the hyperbole of such debates in the present. ${ }^{24}$

In addition to constructing a broad classification scheme about the types of legal problems generated by technological change, it is possible to use a generalized approach to address some common questions. Assume, for example, that a regulatory scheme is proposed to resolve a conflict between a new technology and certain traditional values. Gaia Bernstein has employed non-legal theories of technology, namely theories as to the social shaping of technology and the diffusion process, to draw some general conclusions about the optimum timing of regulatory intervention in technology design. ${ }^{25}$ She suggests that certain indicators of a technology's diffusion may enhance the urgency of intervention. At the same time, the relatively slow pace with which legislatures are able to respond to instabilities generated by ongoing technological change can make legislative intervention at an early stage of technological development undesirable. ${ }^{26}$ It is therefore possible to debate questions as to the best timing and source of regulatory intervention at a generalized level, and we can learn something from decisions made with respect to different technologies in the past.

If law and technology were no more than a series of discussions about particular legal problems whose only connection is the fact that they involve a new gadget or technique, then "law and technology" amounts to no more than

24. Cf. Marita Sturken \& Douglas Thomas, Introduction: Technological Visions and the Rhetoric of the New, in TECHNOLOGICAL VISIONS: THE HoPES AND FEARs that Shape NEW TECHNOLOGIES 1, 6 (Marita Sturken et al., eds., 2004) (arguing the importance of historical framing for understanding the relatively limited impact of technology on society).

25. Gaia Bernstein, When New Technologies are Still New: Windows of Opportunity for Privacy Protection, 51 VILL. L. REV. 921 (2006); Gaia Bernstein, The Paradoxes of Technological Diffusion: Genetic Discrimination and Internet Privacy, 39 CoNN. L. REV. 243 (2006); see also Langdon Winner, Do Artifacts Have Politics, in TECHNOLOGY AND THE FuTURE (Albert H. Teich ed., 10th ed. 2006) 50, 57; Wilbur H. Ferry, Must we Rewrite the Constitution to Control Technology?, SATURDAY REVIEW, Mar. 2, 1968, reprinted in RICHARD C. DORF, TECHNOLOGY SOCIETY AND MAN 15, 18 (1974).

26. Bennett Moses, supra note 9, at 577-580. 
the law of the horse. ${ }^{27}$ If, however, law and technology can be thought of as a series of related problems that law frequently confronts in situations where technology changes, then the focus on law and technology as an area of study is justified. Recognizing the similarities between problems arising in different technological contexts creates the possibility of learning from the consequences of past legal responses to technological change.

\section{ZOOMING IN ON TECHNOLOGICAL CHANGE}

It is not enough to demonstrate that broadening one's perspective to examine the relationship between law and technological change yields useful insights. It is also necessary to prove that one's focus is not unnecessarily narrow. Technological change is only one of many motivations for legal reform. Nothing thus far explains why this Article could not as easily been written about legal problems arising from any improvement in human knowledge, or indeed any social change. This section will argue that there are benefits to looking at the problem of legal reform from the specific angle of technological change.

\section{A. LAW AND SOCIAL CHANGE}

Technological change is one type of social change. If social change is a change in what people think and do, technological change is a change in what they are technically capable of doing. The two are closely related. Philosophers and sociologists have frequently commented on the extent to which technology (understood in its broadest sense) pervades our lives and thinking. ${ }^{28}$ Both excitement and fear of technology's potential can be seen in our media and popular culture. ${ }^{29}$ To some extent, legal scholars write about technology simply because it is an object of fascination. ${ }^{30}$

27. See Frank H. Easterbrook, Cyberspace and the Law of the Horse, 1996 U. CHI. LEGAL F. 207 (1996).

28. E.g., Ellul, supra note 7; MAX Weber, The Protestant ETHIC AND THE SPIRIT OF CAPITALISM 181-82 (Talcott Parsons trans., Sribner 1958); Martin Heidegger, The Question Concerning Technology, in THE QUESTION CONCERNING TECHNOLOGY AND OTHER EssAYs 3 (William Lovitt trans., 1977).

29. Kieran Tranter, Terror in the Texts: Technology - Law - Future, 13 LAW \& CRITIQUE 75 (2002).

30. See Barton Beebe, Law's Empire and the Final Frontier: Legalizing 
But our fears about technology's potential also create a felt need for control through law. Where particular technologies evoke a strong response, as in the case of human reproductive cloning, society's concern may lead to a ban. ${ }^{31}$ Even where the benefits are felt to outweigh the harms, as in the case of in vitro fertilization, there is sometimes a felt need for law to operate as a "limit," so as to allay public anxiety. ${ }^{32}$ The idea of government control of technology is certainly more popular than the notion of government control over social life generally. The reasons for prohibiting or regulating new technologies are to some extent special.

It is not only in the area of regulation that technology raises unique issues. Technological change has an impact on existing legal rules-enhancing uncertainty, making them over-inclusive or under-inclusive, and rendering them obsolete. Although changes in what people do, as well as changes in their capacities, have the potential to raise these same issues, most social change has less of an impact on law than technological change. Technological change is usually more difficult to foresee at the time a law is drafted. Of course, a lawmaker might choose to ignore future possibilities or seek to suppress them; for example, a lawmaker might wish to restrict work on Sundays despite the fact that religious diversity in his society is increasing. A lawmaker might not have the time to craft laws that can deal with every hypothetical. Nevertheless, a lawmaker is less likely to be caught by surprise by mere changes in behavior. The fact that most behavioral change is gradual, and is often subject to a counter-trend, means that debates around law and social change can be distinguished from the reaction to technological change.

The special relationship between legal problems and technological change can be seen by examining the timing of legal problems arising from a combination of technological and behavioral changes. Changes in techniques of reproduction

the Future in the Early Corpus Juris Spatialis, 108 YALE L.J. 1737 (1999) (suggesting that "space law" reflected a desire to increase the extent of law's empire).

31. See, e.g., CAL Health \& SAFEty Code § 24185 (West 2006) (prohibiting human cloning).

32. See REPORT OF THE COMMITTEE OF INQUIRY INTO HUMAN FERTILIZATION AND EMBRYOLOGY, July 1984, cmnd. 9314; Janet Gallagher, Embryos, Eggs and Fetuses: Anxiety and the Law, in REPRODUCTIVE TECHNOLOGIES: Gender, Motherhood AND MEdicine 139, 147 (Michelle Stanworth ed., 1987). 
(such as artificial insemination or in vitro fertilization) will usually be faster than related changes in social attitudes towards reproduction. ${ }^{33}$ Laws may be needed to control a type of activity (such as human reproductive cloning) well before it becomes accepted socially, if it ever does. Other legal problems, such as uncertainty, over-inclusiveness, and underinclusiveness, are likely to affect early users of a new technology. In the context of in vitro fertilization, the first case considering the consequences of harming an embryo arose from conduct in 1973, about five years before the first child conceived in vitro was born. ${ }^{34}$ Early cases dealing with the nature of railroads within the law of property and contract arose well before railroads became a regular means of transporting persons and goods. ${ }^{35}$ The potential for legal problems from technological change comes before full social acceptance, diffusion of the technology, and the resulting social impact. Legal problems associated with technological change are thus more urgent and more difficult to anticipate than legal problems associated with social change. Of course, once a technology becomes widely accepted and used, legal problems associated with that technology become more important.

The fact that technological change poses special problems is reflected in metaphors of the law's failure to keep up with technology. ${ }^{36}$ While technological change is not as sudden as might be imagined (it takes time to move a new product or process from development to invention to innovation to dissemination), it is usually speedier than social change and thus prompts more urgent calls for the law to "catch up." Judges usually feel more comfortable updating the law in light of technological change as compared to social change, perhaps because it is more easily perceived as objective. ${ }^{37}$ While some social changes, such as an outbreak of war or disease, can be as sudden as technological change, they raise very different

33. See Gaia Bernstein, The Socio-Legal Acceptance of New Technologies: A Close Look at Artificial Insemination, 77 WASH. L. REV. 1035 (2002).

34. Del Zio v. Presbyterian Hospital, No. 74 Civ. 3588, 1978 U.S. Dist. LEXIS 14450 (S.D.N.Y. Nov. 14, 1978).

35. See supra note 14.

36. See Bennett Moses, supra note 9, at 515-517.

37. Monroe E. Price \& John F. Duffy, Technological Change and Doctrinal Persistence: Telecommunications Reform in Congress and the Court, 97 Colum. L. REV. 976, 1009 (1997). 
(and quite specific) legal issues. These differences make it worthwhile to consider legal responses to technological change separately from the broader topic of legal responses to behavioral change.

Changes in behavior are not the only example of social change - there are also shifts in social and cultural beliefs and practices. Although such shifts can create pressure for legal reform, like behavioral change, they tend to be more gradual. Attitudes towards legal reform of this type are also different. The shifts prompted by the women's and civil rights movements are reflected in the repeal of discriminatory laws and the enactment of laws prohibiting certain forms of discrimination. However, unlike technological change, reformers rarely argue that the law had ceased to be good law because of social change. Instead, they usually argue that the law was always bad and all that has changed is the social awareness of how bad it was. For example, few would argue today that the legal subordination of African-Americans was ever justified. Legal responses to technological change are not perceived in the same way. Few would suggest that laws regulating railroads were desirable before any track was laid, or that uncertainties regarding the identification of the mother of a child conceived in vitro needed to be resolved before the separation of gestational and genetic motherhood became a technical possibility. Therefore, although changes in belief, like technological changes, generate reasons to change the law, the reasons are of a different type. Changes in the law are rarely justified on the basis of the fact of social change, but rather on the basis of general principles such as justice and fairness.

\section{B. LAW AND CHANGES IN KNOWLEDGE}

Another way in which a theory of law and technological change could be broadened would be to include all changes in social knowledge. Knowing how to achieve particular ends through technological means is but one type of knowledge. There are various other forms of social knowledge, including information about current events and scientific knowledge. Like technology, social knowledge evolves over time as new things are learned and outdated or erroneous notions are discarded. It is therefore arguable that limiting the scope of inquiry to changes in one type of knowledge (knowledge of means to extend human capability) is arbitrarily narrow.

Just as technological change can render legal rules 
uncertain, over-inclusive, under-inclusive, or obsolete, so can acquiring new information. In particular, rules may become obsolete once it is discovered that they were based on false assumptions. ${ }^{38}$ It is easy to imagine ordinary instructions that one might wish to retract had one known all the facts. Some familiar ones include: "drop everything and come here" addressed to a person holding a baby in the bath, 39 "shut the door" spoken by a superior who did not see the CEO approaching, 40 and "buy a packet of curry powder" where the speaker did not realize that the price had recently escalated significantly. ${ }^{41}$ These examples suggest that there is nothing special about the legal problems that arise as a result of technological change-all changes in available information may create incentives for lawmakers to reform laws.

But there is an important difference between rules based on outdated technology and rules based on partial ignorance of circumstances. In formulating legal rules, legislators and administrators $^{42}$ have the option to devote significant resources to ascertaining the truth of the facts on which the new rules are based. 43 While they might devote similar resources to futurist predictions of technological change, such efforts are unlikely to prove fruitful. ${ }^{44}$ Therefore,

38. See Larry Alexander, All or Nothing at All? The Intentions of Authorities and the Authority of Intentions, in LAW AND INTERPRETATION 357, 374 (Andrei Marmor ed., 1997).

39. Anthony D'Amato, Can Legislatures Constrain Judicial Interpretation of Statutes?, 75 VA. L. REV. 561, 569 (1989).

40. Kent Greenawalt, How Law Can be Determinate?, 38 U.C.L.A. L. REV. 1, 8 (1990).

41. Alexander, supra note 38 , at 376-77.

42. Judges do not "formulate" rules in the same way. The interaction between judge-made rules and technological change has different features to the interaction between legislative rules and technological change. See generally Bennett Moses, supra note 9, at 606-07.

43. See Robin Charlow, Judicial Review, Equal Protection and the Problem with Plebiscites, 79 CORNELL L. REV. 527, 578 (1994) (noting that legislatures have "substantial staff, funds, time and procedures to devote to effective information gathering and sorting"). Congress, in particular, can gather information from lobbyists, congressional and committee staffs, legislative hearings, and reports of the Congressional Research Service of the Library of Congress.

44. David E. Nye, Technological Prediction: A Promethean Problem, in TECHNOlOGICAL Visions: THE Hopes AND FEARs THAT SHAPE NEW TECHNOLOGIES 159, 161 (Marita Sturken et al. eds., 2004) (referring to a study demonstrating the common failure of technology predictions made by experts); ALVIN TOFFLER, FUTURE SHOCK 191 (1970) (giving examples of 
technological change is likely to have a more significant impact on law than acquiring additional information on the current state of affairs. If Congress was to pass a law based on mistaken facts, obviously that law could be criticized accordingly, but laws based on mistakes as to existing circumstances are relatively rare. Laws based on mistakes as to existing circumstances also give rise to a different type of critique-lawmakers that misconstrue the facts might be thought careless, but lawmakers are not criticized for failing to anticipate technological change, only for failing to respond promptly after the change has taken place.

Changes in scientific understandings are, however, generally considered as difficult to foresee as changes in technology. Our understanding and perceptions of the natural world change over time, often in revolutionary ways. ${ }^{45}$ Scientific and technological changes are closely related and sometimes hard to differentiate.46 For instance, improvements in our understanding of biology, and in particular the process of fertilization, facilitated the invention of in vitro fertilization and other reproductive technologies. Conversely, most scientific experiments could not take place without the tools created by technologists. ${ }^{47}$

Nevertheless, the types of legal problems that are most closely related to changes in scientific understanding differ from the types of legal problems generated by technological change. Changes in our understanding of the world may alter policy focus (for example, by altering our understandings of what causes both advantages and harm); changes in technology alter what forms of conduct are practicable (thus changing how we might cause advantages or harm). Scientific change can shift the meaning and usefulness of categories, altering the utility of distinctions made in legal rules. ${ }^{48}$ In the

dramatic failures of technology prediction); Eugene Volokh, Book Review, Technology and the Future of Law, 47 STAN. L. REV. 1375, 1375-76 (1995).

45. See generally ThOMAS S. KuHN, The StRUCTURE OF SCIENTIFIC REVOLUTIONS (3d ed. 1996).

46. See Donald MacKenzie \& Judy Wacjman, Introductory Essay, in THE SOCIAL SHAPING OF TECHNOLOGY 1, 9 (Donald MacKenzie \& Judy Wacjman eds., 1st ed. 1985).

47. $I d$.

48. Mark D Janis \& Stephen Smith, Obsolescence in Intellectual Property Regimes 1,10-11 (Legal Studies Research Paper, No. 05-48, University of Iowa 2006) (suggesting that plant variety protection is obsolescent as it distinguishes plant varieties based on phenotype rather than genotype), available at http://ssrn.com/abstract=897728; see also David O. Brink, Legal 
case of technological change, the difficulty tends to be the inclusion or exclusion of a new form of conduct from a particular category, rather than the coherence of the category itself.

The distinctions between the nature of legal problems generated by technological and scientific change are not only technical, but have important practical implications, as well. We can talk about technology-neutral rules, meaning either rules that do not arbitrarily distinguish between different means of achieving the same outcome or rules that are resistant to the sorts of problems generated by technological change. 49 An understanding of the nature of legal problems that result from technological change can help explain what technology-neutral drafting involves. Yet one does not hear demands for scientifically-neutral rules. This is not because one cannot imagine a rule that failed to differentiate between scientific possibilities. The rule "do not do anything that harms the environment," leaves an interpreter to decide whether the manufacture of certain substances, thought by some to promote global warming, would be prohibited. The reason is rather that scientific neutrality offers less social benefits than technological neutrality. It is one thing for the government to say, "here is what we wish to achieve, do so in any way you can" and for it to remain neutral on knowledge claims. Technological neutrality seeks to encourage positive technological change by at least remaining neutral to the possibility of new ways of achieving the same ends. It is extremely unlikely that scientific neutrality would lead to better science.50 Rules tend to be based on both current understandings and existing possibilities, but not in the same way, and not with the same implications.

One final category of knowledge needs to be distinguished from technology. There are unusual cases where knowledge

Theory, Legal Interpretation, and Judicial Review, 17 PHIL. \& PUB. AFF. 105, 128-29 (1988) (noting that a rule maker may use broad language but have in mind a particular example which, due to changes in scientific understanding, no longer fits into the original category).

49. A search on LexisNexis on June 11, 2006 in the category of U.S. and Canadian Law Reviews for "technolog! w/2 neutral" found 506 articles, of which exactly 100 used those terms in a different context. No articles were found on scientifically neutral rules.

50. In fact, the opposite is more likely the case, as researchers employed by regulated corporations would be encouraged to reach "desirable" conclusions. 
changes what is possible in a society, without technological change. For example, the discovery of a previously unknown land mass by a group of people makes colonization possible (provided the means of getting there already exist). Some of the legal controversies generated by these situations are similar to those generated by technological change. However, the creation of a new jurisdiction involves many unique legal issues, and ought therefore to be considered independently.

Changes in different types of knowledge - technical knowhow, information on events, scientific understanding, and discovery of new places-generate very different types of legal issues. Thus the insights gained from a study of legal and technological change will not necessarily apply more broadly.

\section{CONCLUSION}

A theory of law and technology can provide useful insights that assist in examining legal problems surrounding the introduction of particular technologies. It provides a structure through which lessons learned from technologies of the past can help make decisions about how to regulate and adapt to future technologies. It also provides a vehicle for learning from the vast literature on technology written by sociologists, historians, and philosophers. For example, it is commonly accepted that technology is shaped by social and political structures. ${ }^{51}$ Yet critics of technology often complain about society's failure to subject technology to sufficient scrutiny, in particular, in light of its power to alter social relations and social values. ${ }^{2}$ Although the frequent adoption of technologies despite negative externalities may support such theories, the notion of a mindless mass population accepting technology without thought is often overstated. ${ }^{53}$ A deeper problem is the difficulty in translating popular concerns into

51. See Wiebe E. BiJKer, OF Bicycles, BaKelites, AND Bulbs: TOWARDS A THEORY OF SOCIOTECHNICAL CHANGE (1995); THE SocIAL Shaping OF Technology: How The ReFrigerator Got its Hum (D MacKenzie \& J. Wajcman, eds., 2d ed. 1999); Hans K. Klein \& Daniel Lee Kleinman, The Social Construction of Technology: Structural Considerations, 27 SCI., TECH. \& HUM. VALUES 28 (2002).

52. Ellen Rose, The Errors of Thamus: An Analysis of Technology Critique 23 BULL. SCI. TECH. \& Soc. 147, 150 (2003) (discussing Jacques Ellul, Neil Postman, Lewis Mumford, David Noble, and Ursula Franklin).

53. Id. at 151-155; see also Jesper Lassen \& Andrew Jamison, Genetic Technologies Meet the Public: The Discourses of Concern, 31 SCI., TECH. \& Hum. VALUES 8 (2006). 
policy responses. ${ }^{54}$ The interaction between a government's technological policies (its attempts to regulate and facilitate new technologies) and the concrete politics of designing technologies remains poorly understood. ${ }^{55}$ The introduction of lawyers into discourses on technology and society could help fill this gap.

54. Lassen \& Jamison, supra note 53, at 27.

55. See Knut H. Sørensen, Cultural Politics of Technology: Combining Critical and Constructive Interventions, 29 SCI., TECH. \& HUM. VALUES 184, 187 (2004) (noting the distinction between technological policies and politics). 